\title{
PTU-037 UTILITY OF CYST FLUID CEA CUT-OFF OF 192NG/ML IN THE DIAGNOSIS OF MUCINOUS CYSTS OF THE PANCREAS
}

doi:10.1136/gut.2011.239301.165

K Oppong,,$^{1 *} \mathrm{~J}$ Leeds, ${ }^{2}$ K Elamin, ${ }^{3}$ V Wadehra, ${ }^{4}$ R Charnley, ${ }^{1}$ M Nayar ${ }^{1}{ }^{1}$ Freeman Hospital, Newcastle upon Tyne, UK; ${ }^{2}$ Aberdeen Royal Infirmary, Aberdeen, UK; ${ }^{3}$ Torbay District General Hospital, Torbay, UK; ${ }^{4}$ Royal Victoria Infirmary, Newcastle upon Tyne, UK

Introduction The differentiation of mucinous from non-mucinous pancreatic cysts is important because of the malignant potential of the latter. EUS-FNA allows for high resolution imaging of pancreatic cysts as well as sampling for markers (CEA), cytology and a visual assessment of cyst content. The Cooperative cyst study found an elevated fluid CEA (>192 ng/ $\mathrm{ml}$ ) to be the single most accurate test in correctly predicting mucinous cysts with a sensitivity of $73 \%$. The CEA value of $192 \mathrm{ng} / \mathrm{ml}$ has subsequently been widely adopted as a definitive cut-off value.

Methods The aims of the present study were to assess the utility of a cut-off value of $192 \mathrm{ng} / \mathrm{ml}$ in differentiating mucinous from non-mucinous pancreatic cysts and to compare this to general EUS assessment. IPMN and mucinous cyst adenoma/adenocarcinoma (MCA and MCAC) were considered separately. The study population comprised all the patients undergoing EUS-FNA at a tertiary centre for assessment of suspected pancreatic neoplastic cysts between June 2003 and April 2010.

Results During this period 267 procedures were performed on 235 individuals, of whom 71 had a definitive diagnosis (60 resection histology, 5 histology, 6 malignant cytology), cystic degeneration of pancreatic adenocarcinoma (3) being excluded. 68 patients (51 females), (78 procedures) formed the study group. There were 25 mucinous cyst adenomas (11 MCA, 14 MCAC). There were 22 IPMN (2 malignant) and 21 non-mucinous cysts.

For MCA/MCAC using a cut-off of $192 \mathrm{ng} / \mathrm{ml}$ the sensitivity, specificity, accuracy and NPV of detecting a mucinous lesion were $62.5 \%, 94.4 \%, 79.4 \%, 73.9 \%$. Combining EUS morphology, cytology and visual assessment of aspirate (mucoid/non-mucoid) gave figures of $100 \%, 70.8 \%, 86 \%$, $100 \%$. The combination was significantly more sensitive $\mathrm{p}=0.007$, but no significant difference in specificity. ROC area under the curve was numerically greater 0.861 versus 0.785 (not significant).

For the IPMN patients the cut-off $192 \mathrm{ng} / \mathrm{ml}$ showed a sensitivity of $20 \%$ in the diagnosis of IPMN. EUS diagnosis had a sensitivity of $85 \%$. Sensitivity of aspirate appearance: $87 \%$, cytology: 50\%; combining fluid appearance, EUS and cytology: $93 \%$. Comparing the performance of CEA 192 versus combination in differentiating IPMN from non-mucinous cyst, ROC curve area was 0.864 versus $0.623 p=0.02$.

Conclusion A CEA cut-off of $192 \mathrm{ng} / \mathrm{ml}$ demonstrated good specificity and moderate sensitivity in the diagnosis of MCA, however it performed poorly in the diagnosis of IPMN. Combining EUS, aspirate appearance and cytology was significantly more sensitive in diagnosing mucinous cysts with a very high NPV.

Competing interests None.

Keywords endoscopic ultrasonography, pancreatic cystic neoplasm. 